\title{
Electrode Kinetics of the Ni Porous Electrode for Hydrogen Production in a Molten Carbonate Electrolysis Cell (MCEC)
}

\author{
Lan Hu, ${ }^{\mathrm{Z}}$ Göran Lindbergh, and Carina Lagergren* \\ Applied Electrochemistry, Department of Chemical Engineering and Technology, KTH Royal Institute of Technology, \\ SE-100 44 Stockholm, Sweden
}

\begin{abstract}
The purpose of this study was to elucidate the kinetics of a porous nickel electrode for hydrogen production in a molten carbonate electrolysis cell. Stationary polarization data for the Ni electrode were recorded under varying gas compositions and temperatures. The slopes of these iR-corrected polarization curves were analyzed at low overpotential, under the assumption that the porous electrode was under kinetic control with mass-transfer limitations thus neglected. The exchange current densities were calculated numerically by using a simplified porous electrode model. Within the temperature range of $600-650^{\circ} \mathrm{C}$, the reaction order of hydrogen is not constant; the value was found to be $0.49-0.44$ at lower $\mathrm{H}_{2}$ concentration, while increasing to 0.79-0.94 when containing $25-50 \% \mathrm{H}_{2}$. The dependence on $\mathrm{CO}_{2}$ partial pressure increased from 0.62 to 0.86 with temperature. The reaction order of water showed two cases as did hydrogen. For lower $\mathrm{H}_{2} \mathrm{O}$ content (10-30\%), the value was in the range of $0.47-0.67$ at $600-650^{\circ} \mathrm{C}$, while increasing to $0.83-1.07$ with $30-50 \% \mathrm{H}_{2} \mathrm{O}$. The experimentally obtained partial pressure dependencies were high, and therefore not in agreement with any of the mechanisms suggested for hydrogen production in molten carbonate salts in this study. (c) 2015 The Electrochemical Society. [DOI: 10.1149/2.0491509jes] All rights reserved.
\end{abstract}

Manuscript submitted April 21, 2015; revised manuscript received June 8, 2015. Published July 1, 2015. This was Paper 1530 presented at the Chicago, Illinois, Meeting of the Society, May 24-28, 2015.

Electrolysis in molten carbonate salts at high temperatures is a promising method for hydrogen and/or syngas $\left(\mathrm{H}_{2}+\mathrm{CO}\right)$ production, especially when combining it with renewable electricity resources such as solar energy and wind power. Due to the favorable thermodynamic and kinetic conditions, high-temperature electrolysis will attain higher overall efficiency and require lower applied voltage when compared to low-temperature electrolysis. ${ }^{1}$ Electrolysis in molten carbonates has been evidenced by some authors, mainly by converting $\mathrm{CO}_{2}$ into $\mathrm{CO} .{ }^{2-5}$ Peelen et al. ${ }^{2}$ studied the electrochemical reduction of $\mathrm{CO}_{2}$ into $\mathrm{CO}$ on a gold flag electrode in $62 / 38 \mathrm{~mol} \%$ $\mathrm{Li} / \mathrm{K}$ carbonate mixture in the temperature range $575-700^{\circ} \mathrm{C}$. Kaplan et al. ${ }^{3-4}$ observed the conversion of $\mathrm{CO}_{2}$ to $\mathrm{CO}$ by using a cell with a molten electrolyte consisting of lithium carbonate and lithium oxide, in which the electrodes were graphite (anode) and titanium (cathode), and the working temperature was $850-900^{\circ} \mathrm{C}$. Chery et al..$^{5}$ presented thermodynamic calculations and experimental measurements on the reduction of $\mathrm{CO}_{2}$ into $\mathrm{CO}$ on a gold flag or planar disk electrode with $\mathrm{Li} / \mathrm{K}$ and $\mathrm{Li} / \mathrm{Na}$ carbonate eutectics at temperatures from 575 to $650^{\circ} \mathrm{C}$. However, most experiments were carried out on flag electrodes, which are different from porous electrodes when considering electrode surface and mass-transfer limitations. In our previous study ${ }^{6}$ a cell operating at $650^{\circ} \mathrm{C}$, with conventional molten carbonate fuel cell (MCFC) materials (Ni-based porous electrode and molten carbonate electrolyte), was investigated also for electrolysis. The cell was found to give lower polarization losses in MCEC mode than in MCFC mode, mainly due to the $\mathrm{NiO}$ electrode performing much better as anode in the electrolysis cell. Reversing the electrochemical cell will provide new opportunities. The possibility of operating the molten carbonate cell alternatingly as a fuel cell to produce electricity and as an electrolyzer to generate fuel gas may increase the economic benefits.

However, in the previous work, ${ }^{6}$ slightly higher polarization losses on the $\mathrm{Ni}$ electrode were found for water electrolysis compared to hydrogen oxidation when using a fuel gas consisting of 64/16/20\% $\mathrm{H}_{2} / \mathrm{CO}_{2} / \mathrm{H}_{2} \mathrm{O}$. When the $\mathrm{CO}_{2}$ content was increased to $40 \%$, the polarization resistance gave a similar or even a little lower value in the electrolysis cell than in fuel cell mode. To learn more about the use of the cell as an electrolyzer it is of vital importance to elucidate the kinetics and reaction mechanism on the $\mathrm{Ni}$ porous electrode for hydrogen production, as well as to further study the disparity between hydrogen oxidation and water electrolysis (hydrogen production) under molten carbonate conditions. Several studies ${ }^{7-13}$ have been made on the kinetics of hydrogen oxidation in a molten carbonate fuel cell,

*Electrochemical Society Active Member.

${ }^{\mathrm{z}}$ E-mail: lanhu@kth.se see Table I. Ang and Sammells (AS) ${ }^{7}$, and Jewulski and Suski (JS) ${ }^{8}$ suggested that the intermediate species of the charge-transfer step was the hydroxyl ion $\left(\mathrm{OH}^{-}\right)$. Both these two mechanisms show identical reaction orders $(0.25)$ for hydrogen, carbon dioxide and water. $\mathrm{Lu}$ and Selman ${ }^{9}$ agreed with the AS mechanism, and they also noted that the hydrolysis equilibrium reaction played an important role in carbonate melts. Nishina et al. ${ }^{10}$ proposed a modification of the JS mechanism, including a split up of the rate-determining step. The intermediate species $\mathrm{M}-\mathrm{HCO}_{3}{ }^{-}$was mentioned as plausibly rate-determining. But Weewer et al. ${ }^{12}$ showed that the rate-determining step was the first step of producing absorbed hydrogen and hydroxyl ion $\left(\mathrm{OH}^{-}\right)$for $\mathrm{Au}$ and was the final chemical reaction of $\mathrm{OH}^{-}$and $\mathrm{CO}_{2}$ for $\mathrm{Ni}$. This gave a higher dependence on the hydrogen partial pressure. The Ni porous electrode was also experimentally studied for hydrogen oxidation, ${ }^{11,13}$ but the reaction mechanism is still not well defined.

So far, the kinetics and reaction mechanism on a porous $\mathrm{Ni}$ electrode as cathode for hydrogen and/or carbon monoxide production in a molten carbonate electrolysis cell are not known. The overall electrochemical reaction on a $\mathrm{Ni}$ porous electrode for hydrogen production in MCEC mode is

$$
\mathrm{CO}_{2}+\mathrm{H}_{2} \mathrm{O}+2 e^{-} \rightleftharpoons \mathrm{H}_{2}+\mathrm{CO}_{3}^{2-}
$$

Although the kinetics of $\mathrm{CO}_{2}$ electrolysis generating $\mathrm{CO}$ is probably slower than electrolysis of $\mathrm{H}_{2} \mathrm{O}$ producing hydrogen on a Ni-based electrode,${ }^{14}$ there is still the possibility of $\mathrm{CO}$ production through the following reaction

$$
2 \mathrm{CO}_{2}+2 e^{-} \rightleftharpoons \mathrm{CO}+\mathrm{CO}_{3}^{2-}
$$

In this paper Reaction 1 is assumed to be the main electrochemical cathodic reaction and Reaction 2 will therefore not be included when analyzing the experimental data. The general procedure for elucidating the mechanism of Reaction 1 is to determine the dependencies of the exchange current densities on the hydrogen, carbon dioxide and water partial pressures.

The aim of this paper is to determine the reaction orders of hydrogen, carbon dioxide and water. Using these as starting point the kinetics and reaction mechanism on a $\mathrm{Ni}$ porous electrode for producing hydrogen in MCEC mode may be proposed. For this purpose a large amount of polarization data was investigated, concerning the effect of gas composition and temperature on steady-state electrode performance. From the slopes of the iR-corrected polarization curves at low overpotential, the corresponding exchange current densities were evaluated. Based on that, the partial pressure dependencies of hydrogen, carbon dioxide and water could be determined. 


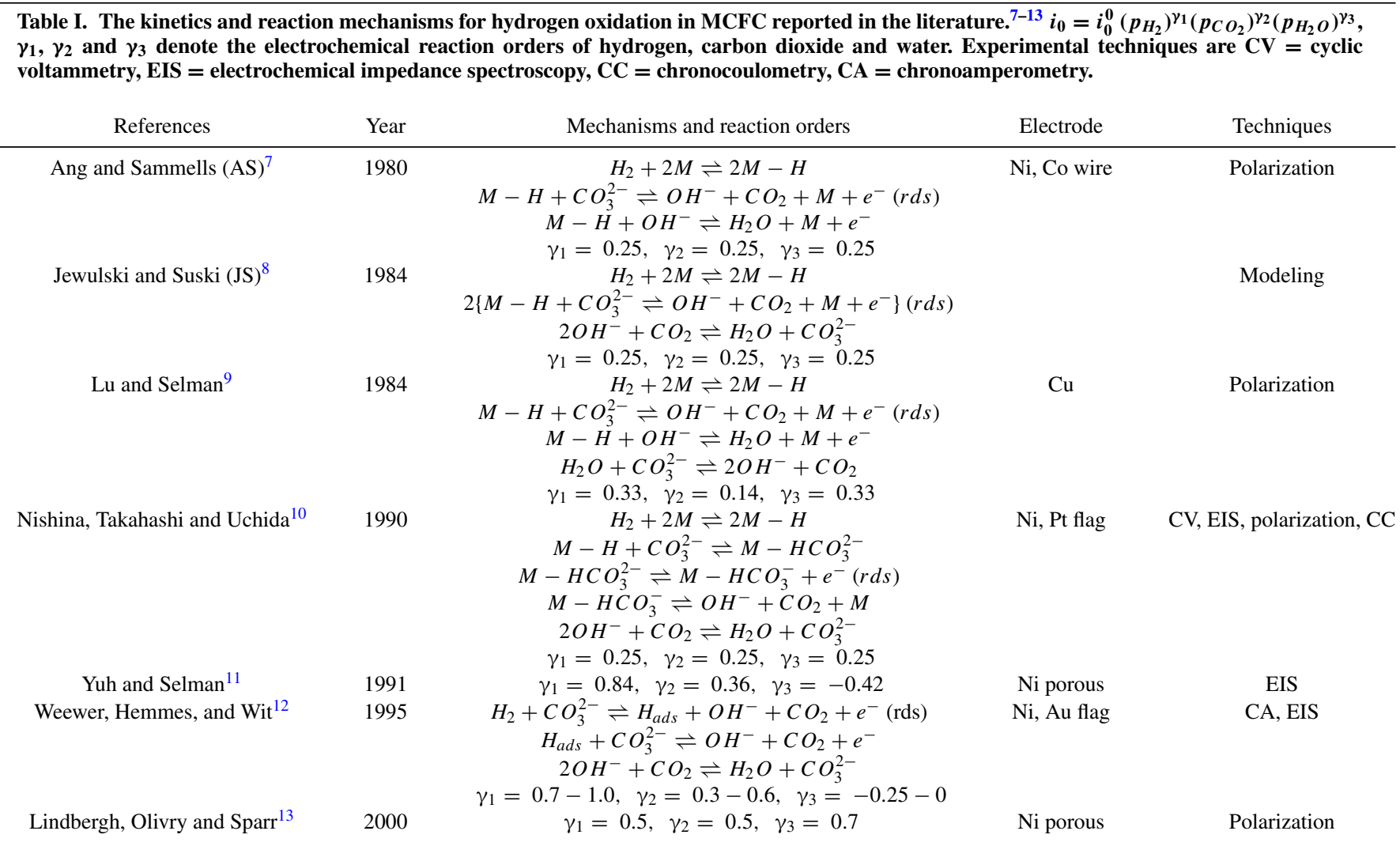

\section{Experimental}

Experimental data were obtained from a $3 \mathrm{~cm}^{2}$ laboratory cell unit, where the cell components were provided by Ansaldo Fuel Cells, Italy. The cell has a porous $\mathrm{Ni}-\mathrm{Cr}$ alloy as hydrogen electrode (cathode), and a porous $\mathrm{Ni}$, oxidized and lithiated in situ, as oxygen electrode (anode). The electrodes are separated by a porous $\mathrm{LiAlO}_{2}$ matrix, which also supports the electrolyte, a eutectic mixture of $62 / 38 \mathrm{~mol} \% \mathrm{Li}_{2} \mathrm{CO}_{3} / \mathrm{K}_{2} \mathrm{CO}_{3}$. The current collectors on the cathode and anode sides are made of nickel and stainless steel SS316, respectively. Each current collector has two probes, one for measuring the current and one for the potential measurement. The reference electrode consists of gold wires in equilibrium with a gas mixture containing 33/67\% $\mathrm{O}_{2} / \mathrm{CO}_{2}$. Two identical reference electrodes are placed in separate chambers filled with the same electrolyte as in the cell. These chambers are connected to the cell through a capillary with a gold plug. The laboratory cell set-up used in this study is the same as that used in the previous study, and a schematic drawing is found in Ref. 6.

The cell was operated at three different temperatures, 600,625 and $650^{\circ} \mathrm{C}$. A gas consisting of $15 / 30 / 55 \% \mathrm{O}_{2} / \mathrm{CO}_{2} / \mathrm{N}_{2}$ was used for the $\mathrm{NiO}$ oxygen electrode. Different fuel gas mixtures of $\mathrm{H}_{2} / \mathrm{CO}_{2} / \mathrm{H}_{2} \mathrm{O} / \mathrm{N}_{2}$ for the $\mathrm{Ni}$ electrode and their equilibrium conditions are described in the following section. The concentration of $\mathrm{H}_{2} \mathrm{O}$ in the fuel gases is controlled by the temperature of the water in the humidifier. In order to reduce the effect of mass-transport limitations in the gaseous phase, ${ }^{13}$ the flow rate of inlet gases was held high, at approximately $250 \mathrm{ml} \cdot \mathrm{min}^{-1}$ for the $\mathrm{Ni}$ electrode. The gas flow rate for the $\mathrm{NiO}$ electrode was also about $250 \mathrm{ml} \cdot \mathrm{min}^{-1}$, while the reference gas had a flow rate of $20 \mathrm{ml} \cdot \mathrm{min}^{-1}$. All the gases used in the experiments are certified gas mixtures from AGA Gas AB, Sweden.

The polarization curves for the Ni electrode were measured using a Solartron Interface SI1287 supported by CorrWare software. The current-interrupt method was used to correct for the ohmic potential drop. The negative current density refers to the electrolysis mode, shown in the figures below.

\section{Fuel Gases and Their Equilibrium Conditions}

The inlet fuel gases were varied separately within three different groups, see Table II. The concentration increment was 5\% when increasing the amount of hydrogen (5-50\%), carbon dioxide (10-50\%) and water $(10-50 \%)$, respectively.

Due to different reactions possibly taking place at the Ni electrode, an essential problem is to know the actual gas composition inside the cell when determining the partial pressure dependencies. One such reaction is the reversed water-gas shift reaction

$$
\mathrm{H}_{2}+\mathrm{CO}_{2} \rightleftharpoons \mathrm{H}_{2} \mathrm{O}+\mathrm{CO}
$$

At higher temperatures (above $500^{\circ} \mathrm{C}$ ), and in the presence of a nickel catalyst, the shift reaction will very rapidly establish equilibrium of these gases. ${ }^{15}$ Therefore Reaction 3 will affect the gas compositions inside the cell and then probably influence the performance of the $\mathrm{Ni}$ electrode. The equilibrium constant

$$
K_{p}=\frac{P_{\mathrm{H}_{2} \mathrm{O}} \cdot P_{\mathrm{CO}}}{P_{\mathrm{H}_{2}} \cdot P_{\mathrm{CO}_{2}}}
$$

can be found and calculated in the literature for $600^{\circ} \mathrm{C}\left(K_{p}=0.373\right)$ and $650^{\circ} \mathrm{C}\left(K_{p}=0.510\right),{ }^{9,11}$ while being interpolated for the value at $625^{\circ} \mathrm{C}\left(K_{p}=0.442\right)$. The fuel gas compositions calculated at shift equilibrium at $600-650^{\circ} \mathrm{C}$ are shown in Table III.

Table II. Inlet fuel gas compositions using an increment of $5 \%$ when changing the concentrations of $\mathrm{H}_{2}, \mathrm{CO}_{2}$, and $\mathrm{H}_{2} \mathrm{O}$, respectively.

\begin{tabular}{ccccc} 
Gas Group No. & $\mathrm{H}_{2} / \%$ & $\mathrm{CO}_{2} / \%$ & $\mathrm{H}_{2} \mathrm{O} / \%$ & $\mathrm{~N}_{2} / \%$ \\
\hline 1 & $\mathbf{5 - 5 0}$ & 25 & 25 & Balance \\
2 & 25 & $\mathbf{1 0 - 5 0}$ & 25 & Balance \\
3 & 25 & 25 & $\mathbf{1 0 - 5 0}$ & Balance
\end{tabular}


Table III. Gas compositions calculated at shift equilibrium at $600-650^{\circ} \mathrm{C}$, in percent $(\%)$.

\begin{tabular}{|c|c|c|c|c|c|c|c|c|c|c|c|c|c|}
\hline \multirow[b]{2}{*}{ No. } & \multicolumn{4}{|c|}{$600^{\circ} \mathrm{C}$} & \multicolumn{4}{|c|}{$625^{\circ} \mathrm{C}$} & \multicolumn{4}{|c|}{$650^{\circ} \mathrm{C}$} & \multirow[b]{2}{*}{$\mathrm{N}_{2}$} \\
\hline & $\mathrm{H}_{2}$ & $\mathrm{CO}_{2}$ & $\mathrm{H}_{2} \mathrm{O}$ & $\mathrm{CO}$ & $\mathrm{H}_{2}$ & $\mathrm{CO}_{2}$ & $\mathrm{H}_{2} \mathrm{O}$ & $\mathrm{CO}$ & $\mathrm{H}_{2}$ & $\mathrm{CO}_{2}$ & $\mathrm{H}_{2} \mathrm{O}$ & $\mathrm{CO}$ & \\
\hline \multicolumn{14}{|c|}{ Group 1: An increase of $\mathrm{H}_{2}(5-50 \%)$ in the inlet fuel gases } \\
\hline 1.1 & 3.74 & 23.74 & 26.26 & 1.26 & 3.59 & 23.59 & 26.41 & 1.41 & 3.45 & 23.45 & 26.55 & 1.55 & 45 \\
\hline 1.2 & 7.64 & 22.64 & 27.36 & 2.36 & 7.37 & 22.37 & 27.63 & 2.63 & 7.12 & 22.12 & 27.88 & 2.88 & 40 \\
\hline 1.3 & 11.67 & 21.67 & 28.33 & 3.33 & 11.30 & 21.30 & 28.70 & 3.70 & 10.96 & 20.96 & 29.04 & 4.04 & 35 \\
\hline 1.4 & 15.80 & 20.80 & 29.20 & 4.20 & 15.35 & 20.35 & 29.65 & 4.65 & 14.94 & 19.94 & 30.06 & 5.06 & 30 \\
\hline $1.5^{*}$ & 20.02 & 20.02 & 29.98 & 4.98 & 19.49 & 19.49 & 30.51 & 5.51 & 19.03 & 19.03 & 30.97 & 5.97 & 25 \\
\hline 1.6 & 24.30 & 19.30 & 30.70 & 5.70 & 23.72 & 18.72 & 31.28 & 6.28 & 23.22 & 18.22 & 31.78 & 6.78 & 20 \\
\hline 1.7 & 28.65 & 18.65 & 31.35 & 6.35 & 28.02 & 18.02 & 31.98 & 6.98 & 27.47 & 17.47 & 32.53 & 7.53 & 15 \\
\hline 1.8 & 33.04 & 18.04 & 31.96 & 6.96 & 32.38 & 17.38 & 32.62 & 7.62 & 31.80 & 16.80 & 33.20 & 8.20 & 10 \\
\hline 1.9 & 37.48 & 17.48 & 32.52 & 7.52 & 36.78 & 16.78 & 33.22 & 8.22 & 36.18 & 16.18 & 33.82 & 8.82 & 5 \\
\hline 1.10 & 41.96 & 16.96 & 33.04 & 8.04 & 41.24 & 16.24 & 33.76 & 8.76 & 40.60 & 15.60 & 34.40 & 9.40 & 0 \\
\hline \multicolumn{14}{|c|}{ Group 2: An increase of $\mathrm{CO}_{2}(10-50 \%)$ in the inlet fuel gases } \\
\hline 2.1 & 22.64 & 7.64 & 27.36 & $2.36^{\prime}$ & 22.37 & 7.37 & 27.63 & 2.63 & 22.12 & 7.12 & 27.88 & 2.88 & 40 \\
\hline 2.2 & 21.67 & 11.67 & 28.33 & 3.33 & 21.30 & 11.30 & 28.70 & 3.70 & 20.96 & 10.96 & 29.04 & 4.04 & 35 \\
\hline 2.3 & 20.80 & 15.80 & 29.20 & 4.20 & 20.35 & 15.35 & 29.65 & 4.65 & 19.94 & 14.94 & 30.06 & 5.06 & 30 \\
\hline $2.4^{*}$ & 20.02 & 20.02 & 29.98 & 4.98 & 19.49 & 19.49 & 30.51 & 5.51 & 19.03 & 19.03 & 30.97 & 5.97 & 25 \\
\hline 2.5 & 19.30 & 24.30 & 30.70 & 5.70 & 18.72 & 23.72 & 31.28 & 6.28 & 18.22 & 23.22 & 31.78 & 6.78 & 20 \\
\hline 2.6 & 18.65 & 28.65 & 31.35 & 6.35 & 18.02 & 28.02 & 31.98 & 6.98 & 17.47 & 27.47 & 32.53 & 7.53 & 15 \\
\hline 2.7 & 18.04 & 33.04 & 31.96 & 6.96 & 17.38 & 32.38 & 32.62 & 7.62 & 16.80 & 31.80 & 33.20 & 8.20 & 10 \\
\hline 2.8 & 17.48 & 37.48 & 32.52 & 7.52 & 16.78 & 36.78 & 33.22 & 8.22 & 16.18 & 36.18 & 33.82 & 8.82 & 5 \\
\hline 2.9 & 16.96 & 41.96 & 33.04 & 8.04 & 16.24 & 41.24 & 33.76 & 8.76 & 15.60 & 40.60 & 34.40 & 9.40 & 0 \\
\hline \multicolumn{14}{|c|}{ Croup 3: An increase of $\mathrm{H}_{2} \mathrm{O}(10-50 \%)$ in the inlet fuel gases } \\
\hline 3.1 & 17.95 & 17.95 & 17.05 & $7.05^{1}$ & 17.40 & 17.40 & 17.60 & 7.60 & 16.92 & 16.92 & 18.08 & 8.08 & 40 \\
\hline 3.2 & 18.79 & 18.79 & 21.21 & 6.21 & 18.24 & 18.24 & 21.76 & 6.76 & 17.76 & 17.76 & 22.24 & 7.24 & 35 \\
\hline 3.3 & 19.47 & 19.47 & 25.53 & 5.53 & 18.93 & 18.93 & 26.07 & 6.07 & 18.46 & 18.46 & 26.54 & 6.54 & 30 \\
\hline $3.4^{*}$ & 20.02 & 20.02 & 29.98 & 4.98 & 19.49 & 19.49 & 30.51 & 5.51 & 19.03 & 19.03 & 30.97 & 5.97 & 25 \\
\hline 3.5 & 20.47 & 20.47 & 34.53 & 4.53 & 19.97 & 19.97 & 35.03 & 5.03 & 19.52 & 19.52 & 35.48 & 5.48 & 20 \\
\hline 3.6 & 20.86 & 20.86 & 39.14 & 4.14 & 20.37 & 20.37 & 39.63 & 4.63 & 19.94 & 19.94 & 40.06 & 5.06 & 15 \\
\hline 3.7 & 21.18 & 21.18 & 43.82 & 3.82 & 20.72 & 20.72 & 44.28 & 4.28 & 20.30 & 20.30 & 44.70 & 4.70 & 10 \\
\hline 3.8 & 21.46 & 21.46 & 48.54 & 3.54 & 21.02 & 21.02 & 48.98 & 3.98 & 20.61 & 20.61 & 49.39 & 4.39 & 5 \\
\hline 3.9 & 21.70 & 21.70 & 53.30 & 3.30 & 21.28 & 21.28 & 53.72 & 3.72 & 20.89 & 20.89 & 54.11 & 4.11 & 0 \\
\hline
\end{tabular}

*The standard inlet gas, $25 / 25 / 25 / 25 \% \mathrm{H}_{2} / \mathrm{CO}_{2} / \mathrm{H}_{2} \mathrm{O} / \mathrm{N}_{2}$.

\section{Theory}

When analyzing kinetic data for a porous electrode, it is important to consider the current distribution along the depth of the electrode. ${ }^{16}$ The current distribution is determined by the combination of the electrode intrinsic activity, its specific surface area, the effective conductivities of the electrolyte and electrode, and the effective diffusion path lengths of electroactive species. The exchange current density $i_{0}$, varying with the concentration of the electroactive species and temperature, is determined by the reaction mechanism. In this study, exchange current densities are obtained by analyzing iR-corrected polarization curves at low overpotential. In this region the relation between overpotential and current density is linear and it is assumed that the electrode is mainly under kinetic control and that mass-transfer limitations may be neglected.

Lagergren and Simonsson ${ }^{16,17}$ derived the expression for the total polarization resistance for a porous electrode when taking the current distribution into account. For the porous $\mathrm{Ni}$ electrode, the effective conductivity of the solid material is high (about $10^{5} \mathrm{~S} \cdot \mathrm{m}^{-1}$ ) and does not contribute to the polarization resistance, leaving a simplified expression (see Ref. 13):

$$
\frac{d \eta}{d i}=\sqrt{\frac{R T}{n F S i_{0} \kappa}}
$$

where $\kappa$ is the effective conductivity in the electrolyte phase. $S$ is the exterior surface area of the agglomerates, where the dominating part of the electrode reaction takes place.

The porosity of the electrode is determined to be $53.7 \%$, and the effective conductivity in the pore electrolyte is assumed to be $5.0 \mathrm{~S} \cdot \mathrm{m}^{-1}$ at $650^{\circ} \mathrm{C} .{ }^{13}$ Based on that, the effective electrolyte con- ductivities can be calculated for 600 and $625^{\circ} \mathrm{C}$, using the Arrhenius equation, ${ }^{18}$ see Table IV. It is assumed that the electrode reaction occurs mainly on the exterior surface area of the agglomerates. ${ }^{13} \mathrm{By}$ assuming that the agglomerates are spherical and have a radius of approximately $4.5 \mu \mathrm{m}$, the exterior agglomerate surface area, $S$, is estimated to be $2.7 \cdot 10^{5} \mathrm{~m}^{-1} \cdot{ }^{19}$ Furthermore, the electrochemically active area is assumed to be constant for all gas compositions, and will therefore only affect the value of the exchange current density and not the partial pressure dependencies. ${ }^{13}$ All parameter values of the electrode and electrolyte used for solving Eq. 5 are listed in Table IV.

The dependencies of the exchange current density on hydrogen, carbon dioxide and water partial pressures can be calculated from the following equation

$$
i_{0}=i_{0}^{0}\left(p_{\mathrm{H}_{2}}\right)^{a}\left(p_{\mathrm{CO}_{2}}\right)^{b}\left(p_{\mathrm{H}_{2} \mathrm{O}}\right)^{c}
$$

The above equation can also be written in logarithmic form

$$
\log \left(i_{0}\right)=\log \left(i_{0}^{0}\right)+a \log \left(p_{\mathrm{H}_{2}}\right)+b \log \left(p_{\mathrm{CO}_{2}}\right)+c \log \left(p_{\mathrm{H}_{2} \mathrm{O}}\right)
$$

\begin{tabular}{|c|c|c|c|c|}
\hline & & $600^{\circ} \mathrm{C}$ & $625^{\circ} \mathrm{C}$ & $650^{\circ} \mathrm{C}$ \\
\hline$S$ & $2.7 \cdot 10^{5} \mathrm{~m}^{-1}$ & & & \\
\hline $\begin{array}{l}n \\
\kappa\end{array}$ & 2 & $4.1 \mathrm{~S} \cdot \mathrm{m}^{-1}$ & $4.6 \mathrm{~S} \cdot \mathrm{m}^{-1}$ & $5.0 \mathrm{~s} \cdot \mathrm{m}^{-1}$ \\
\hline
\end{tabular}

\footnotetext{
Table IV. The parameter values of the electrode and electrolyte used for Eq. 11.
} 

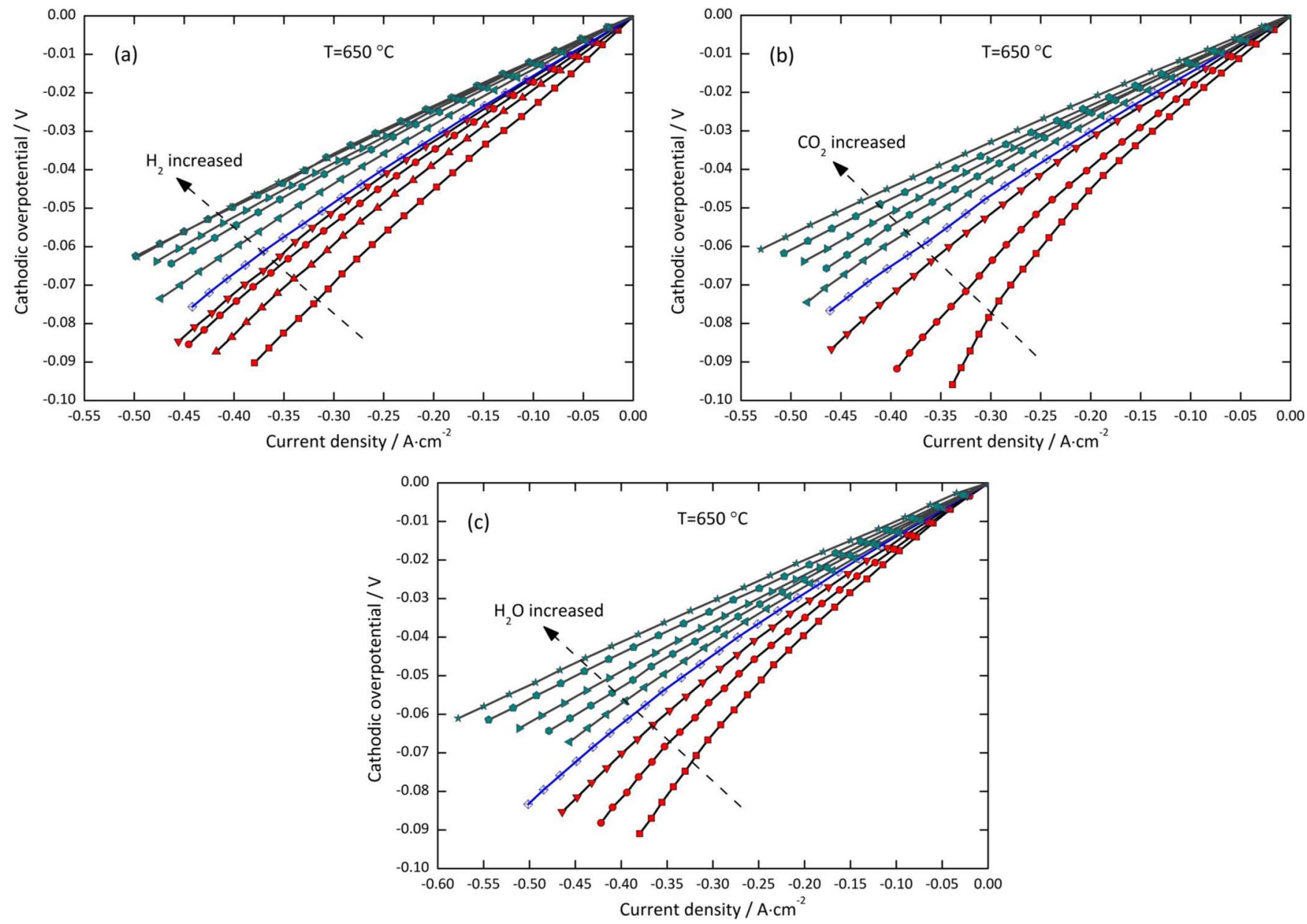

Figure 1. iR-corrected polarization curves for the $\mathrm{Ni}$ electrode in electrolysis cell at $650^{\circ} \mathrm{C}$ with varied gas compositions. (a) $\mathrm{H}_{2}$, (b) $\mathrm{CO}_{2}$, and (c) $\mathrm{H}_{2} \mathrm{O}$.

where $i_{0}^{0}$ is the standard exchange current density, and $a, b$ and $c$ denote the reaction orders of hydrogen, carbon dioxide and water, respectively.

\section{Results and Discussion}

In order to obtain the kinetic data for the hydrogen-production reaction, the electrochemical performance of the Ni electrode in MCEC mode is investigated. Fig. 1 shows the iR-corrected polarization curves for different gas compositions at $650^{\circ} \mathrm{C}$. The blue curves in all the figures correspond to the performance of the $\mathrm{Ni}$ electrode with the standard inlet gas containing $25 / 25 / 25 / 25 \% \mathrm{H}_{2} / \mathrm{CO}_{2} / \mathrm{H}_{2} \mathrm{O} / \mathrm{N}_{2}$. The red and green symbols refer to the lower and higher contents, respectively, compared to the standard concentration of $25 \%$ when changing $\mathrm{H}_{2}, \mathrm{CO}_{2}$ and $\mathrm{H}_{2} \mathrm{O}$ partial pressures separately. When increasing the concentration of $\mathrm{H}_{2}$ in the inlet fuel gases, the polarization losses of the Ni electrode decrease gradually. When containing close to $50 \%$ $\mathrm{H}_{2}$, no improvement or only a small improvement of the electrode performance is shown, see Fig. 1a. At lower $\mathrm{H}_{2}$ content the downward bending tendency of the polarization curves can be observed at high current density, corresponding to mass-transfer limitations. The bending seems to take place more obviously at lower $\mathrm{CO}_{2}$ and $\mathrm{H}_{2} \mathrm{O}$ concentrations, Figs. $1 \mathrm{~b}$ and $1 \mathrm{c}$ (red symbols), respectively. This makes sense since carbon dioxide and water are reactants in the electrolysis cell. An increase of $\mathrm{CO}_{2}$ content improves the $\mathrm{Ni}$ electrode for hydrogen production in the electrolyzer operation. Similarly, the electrode polarization decreases when the water partial pressure is raised. The effect of cell temperature on the polarization of the Ni electrode in the electrolysis cell is also investigated, showing an example for the standard inlet gas in Fig. 2. The performance of the Ni electrode increases strongly from 600 to $625^{\circ} \mathrm{C}$, but much less improvement is found when going from 625 to $650^{\circ} \mathrm{C}$.

From Figs. 1 and 2, it shows that all these iR-corrected curves are approximately linear in the low overpotential range, $<40 \mathrm{mV}$. It is assumed that the electrode in this range is mainly under kinetic control, where mass-transfer limitations are negligible. The polarization resistances, $\frac{d \eta}{d i}$, are obtained from the slopes of these curves by linear

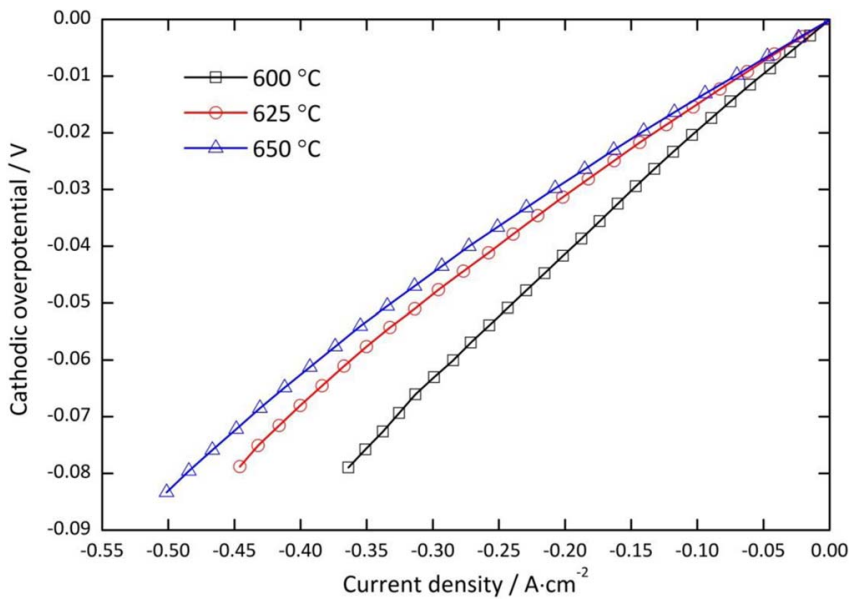

Figure 2. iR-corrected polarization curves for the $\mathrm{Ni}$ electrode in electrolysis cell with the gas of $25 / 25 / 25 / 25 \% \mathrm{H}_{2} / \mathrm{CO}_{2} / \mathrm{H}_{2} \mathrm{O} / \mathrm{N}_{2}$ at operating temperatures from 600 to $650^{\circ} \mathrm{C}$. 

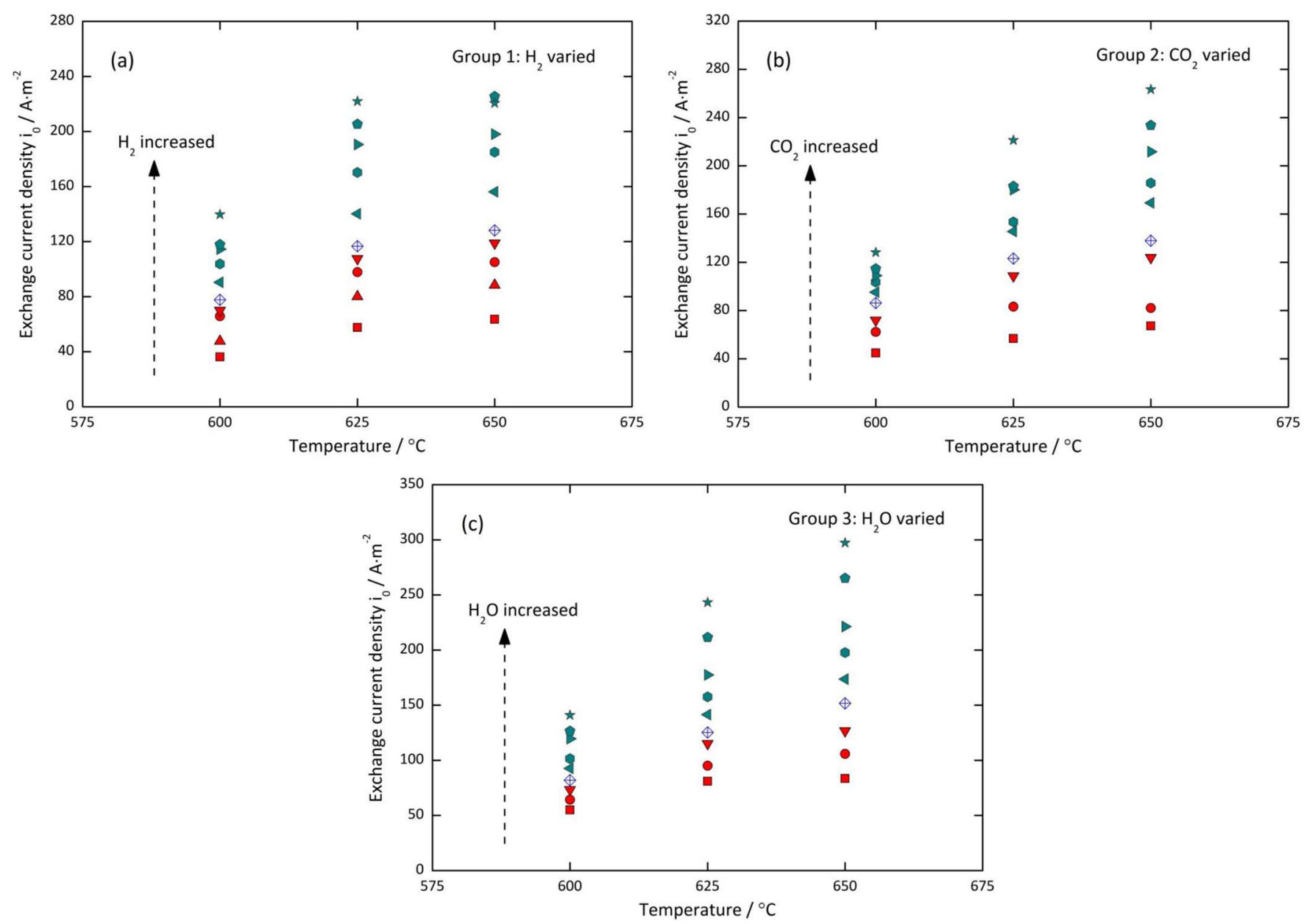

Figure 3. Exchange current densities as function of temperature with varied gas compositions. (a) $\mathrm{H}_{2}$, (b) $\mathrm{CO}_{2}$, and (c) $\mathrm{H}_{2} \mathrm{O}$.

regression analysis. The effect of gas composition on the electrolyte distribution in the electrode is not considered in the evaluation of these experimental data, even though the electrolyte wetting properties of the $\mathrm{Ni}$ electrode strongly depend on gas composition. ${ }^{20}$

The exchange current densities $i_{0}$ can be determined by solving Eq. 5, using the parameter values listed in Table IV. The exchange current densities as function of temperature for different inlet fuel gases are presented in Fig. 3. The exchange current densities for the standard feeding gas, $25 / 25 / 25 / 25 \% \mathrm{H}_{2} / \mathrm{CO}_{2} / \mathrm{H}_{2} \mathrm{O} / \mathrm{N}_{2}$, are calculated to be in the ranges of $80-85,115-125$, and $130-150 \mathrm{~A} \cdot \mathrm{m}^{-2}$ at 600 , 625 and $650^{\circ} \mathrm{C}$, respectively. The exchange current densities obtained in electrolysis operation are higher than the values reported for the porous $\mathrm{Ni}$ electrode operating in fuel cell mode. ${ }^{13}$ Due to the various measuring techniques, calculating methods and operating conditions, it is difficult to directly compare the kinetic data reported by different researchers.

When the temperature rises from 600 to $625^{\circ} \mathrm{C}$, the exchange current densities increase significantly for these three different groups of gas compositions. But when going from 625 to $650^{\circ} \mathrm{C}$ the increase is much less. At $600^{\circ} \mathrm{C}$ the exchange current densities are in the range of $40-140 \mathrm{~A} \cdot \mathrm{m}^{-2}$ under all measured gas compositions. In Fig. 3a and $3 b$ the respective increases of the $\mathrm{H}_{2}$ and $\mathrm{CO}_{2}$ concentration give exchange current densities approximately in the interval of 60-220 $\mathrm{A} \cdot \mathrm{m}^{-2}$ at $625^{\circ} \mathrm{C}$, while these values lie in a slightly higher range, $80-245 \mathrm{~A} \cdot \mathrm{m}^{-2}$, when increasing water content from 10 to $50 \%$, seen in Fig. 3c. A similar tendency is seen at the operating temperature of $650^{\circ} \mathrm{C}$. The ranges of exchange current densities are 65-220, 65-265, and $85-300 \mathrm{~A} \cdot \mathrm{m}^{-2}$ for increasing $\mathrm{H}_{2}, \mathrm{CO}_{2}$, and $\mathrm{H}_{2} \mathrm{O}$ concentrations in the inlet gas compositions, respectively.
On the basis of exchange current densities obtained above, the partial pressure dependencies of hydrogen, carbon dioxide, and water could be determined. Sparr et al. ${ }^{21}$ evidenced that the reversed water-gas shift reaction is not in equilibrium for small cells in molten carbonate salts, in spite of the fact that the reaction is assumed to establish equilibrium rapidly. ${ }^{15}$ Due to the uncertainty of the gas compositions reaching equilibrium or not in this study, two cases with different gas compositions are investigated: (a) no shift reaction occurs (using the inlet gas compositions in Table II) and (b) complete equilibrium is established due to the shift reaction (gas compositions calculated in Table III). Both these cases are presented in Figs. 4-6. The reaction orders can be determined from the slopes by fitting the parameters $a, b$, and $c$ in Eq. 7. And the results from the fitting are presented in Tables V and VI for the cases of the inlet gas compositions and complete equilibrium gas compositions, respectively.

In Fig. 4a, the effect of hydrogen partial pressure on the exchange current density is shown, and it can be seen that the result is not a straight line. In this case the hydrogen partial pressure dependency could be evaluated in two ways. At first, the obtained data points are fitted to straight lines by means of linear regression (solid lines), resulting in values of $0.57-0.59$ for hydrogen at $600-650^{\circ} \mathrm{C}$. Secondly, the data points are fitted to curves in a more accurate way, resulting in different dependencies for different hydrogen concentration intervals (dashed lines). In Tables V and VI, the superscripts marked 1 and 2 refer to the low and high concentration, respectively. The reaction order of hydrogen is in the range of $0.49-0.44\left(a^{1}\right)$ when containing $5-25 \% \mathrm{H}_{2}$ in the inlet gases. Then the partial pressure dependency increases to the interval of $0.79-0.94\left(a^{2}\right)$ within the $\mathrm{H}_{2}$ content range 

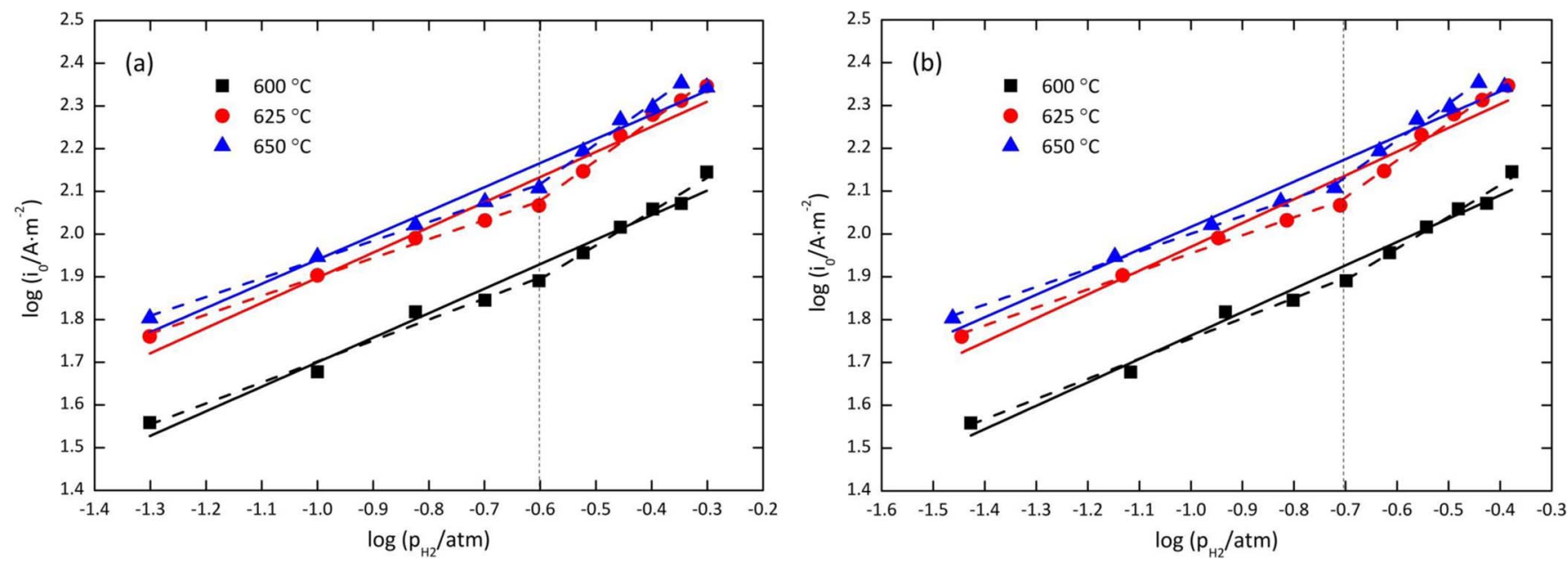

Figure 4. Effect of hydrogen partial pressure on the exchange current density at $600-650^{\circ} \mathrm{C}$. (a) $\mathrm{p}\left(\mathrm{H}_{2}\right)$ from the inlet gas compositions, (b) $\mathrm{p}\left(\mathrm{H}_{2}\right)$ from the gas compositions calculated at shift equilibrium. The vertical dotted line marks the point for change of slopes.
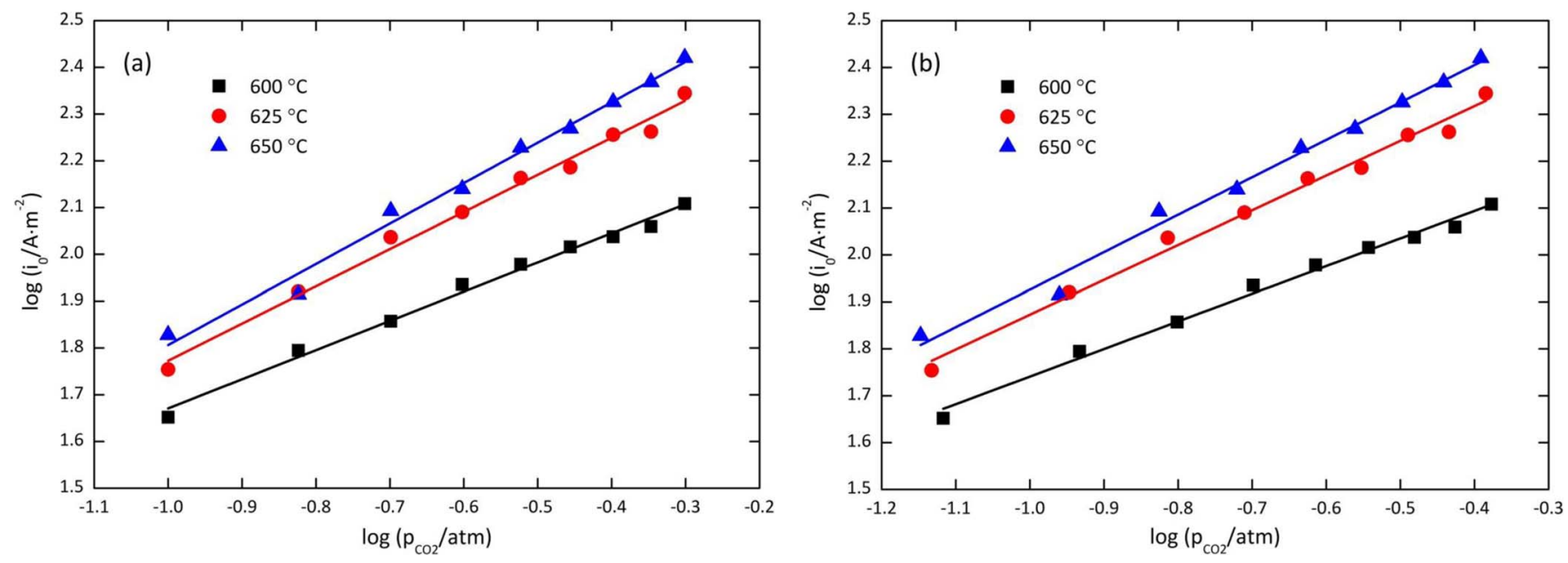

Figure 5. Effect of carbon dioxide partial pressure on the exchange current density at $600-650^{\circ} \mathrm{C}$. (a) $\mathrm{p}\left(\mathrm{CO}_{2}\right)$ from the inlet gas compositions, (b) $\mathrm{p}(\mathrm{CO} 2)$ from the gas compositions calculated at shift equilibrium.
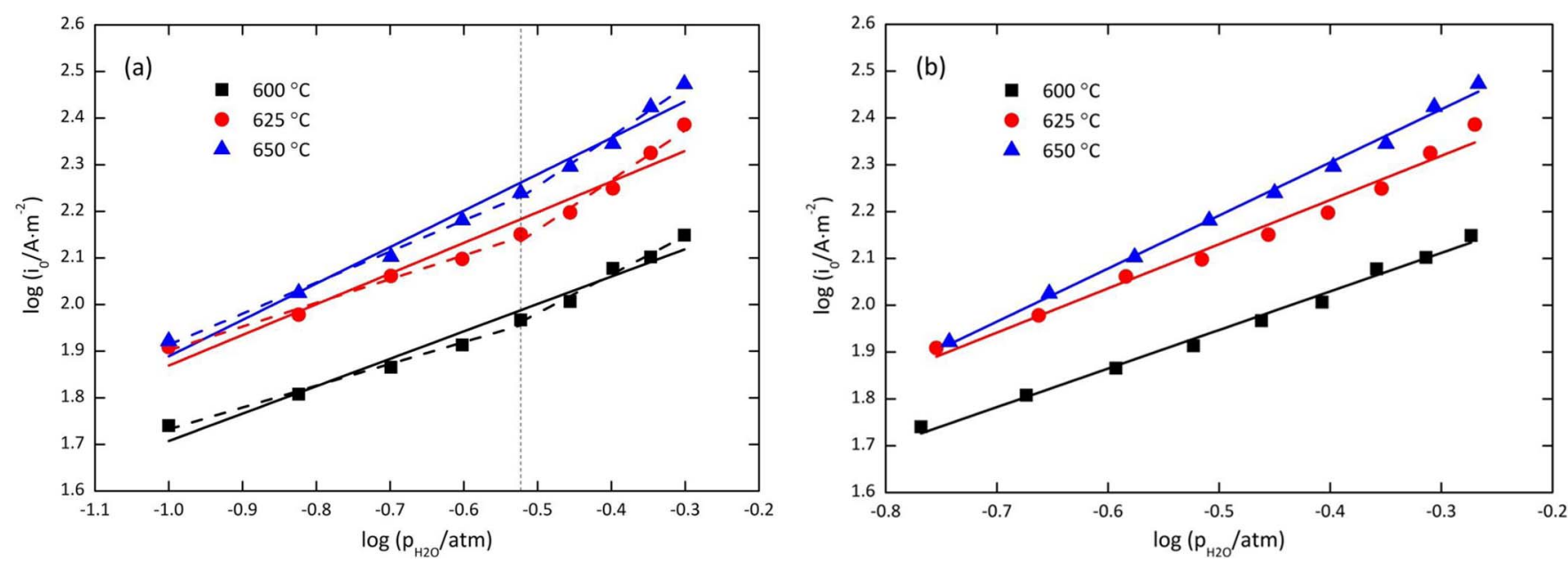

Figure 6. Effect of water partial pressure on the exchange current density at $600-650^{\circ} \mathrm{C}$. (a) $\mathrm{p}\left(\mathrm{H}_{2} \mathrm{O}\right)$ from the inlet gas compositions, (b) $\mathrm{p}\left(\mathrm{H}_{2} \mathrm{O}\right)$ from the gas compositions calculated at shift equilibrium. The vertical dotted line marks the point for change of slopes. 
Table V. The dependency of exchange current densities on the partial pressure of the inlet fuel gas compositions $i_{0}=i_{0}^{0}\left(p_{\mathrm{H}_{2}}\right)^{a}\left(p_{\mathrm{CO}}\right)^{b}\left(p_{\mathrm{H}_{2}} \mathrm{O}\right)^{c}$. The superscripts 1 and 2 refer to the low and high concentration.

$a$

\begin{tabular}{|c|c|c|c|c|c|c|c|}
\hline \multirow[b]{2}{*}{ Temperature $/{ }^{\circ} \mathrm{C}$} & & \multirow[b]{2}{*}{$b$} & \\
\hline & $a$ & $a^{1}\left(5-25 \% \mathrm{H}_{2}\right)$ & $a^{2}\left(25-50 \% \mathrm{H}_{2}\right)$ & & $c$ & $a^{1}\left(10-30 \% \mathrm{H}_{2} \mathrm{O}\right)$ & $a^{2}\left(30-50 \% \mathrm{H}_{2} \mathrm{O}\right)$ \\
\hline 600 & 0.57 & 0.49 & 0.79 & 0.62 & 0.59 & 0.47 & 0.83 \\
\hline 625 & 0.59 & 0.44 & 0.94 & 0.79 & 0.66 & 0.51 & 1.07 \\
\hline 650 & 0.57 & 0.44 & 0.94 & 0.86 & 0.78 & 0.67 & 1.07 \\
\hline
\end{tabular}

of $25-50 \%$. Regardless of the way of evaluating data, the reaction order of hydrogen does not strongly depend on the temperature in any of the concentration intervals. In Fig. $4 \mathrm{~b}$ the water-gas shift reaction is taken into account when calculating the gas compositions. However, similar dependencies of hydrogen partial pressure as in Fig. 4a are found (listed in Table VI). Thus, the reversed water-gas shift reaction seems to have small effect, if any, on the hydrogen partial pressure dependency.

Unlike the case of hydrogen, the reaction order of carbon dioxide is dependent on the temperature, see Fig. 5a. The values are 0.62 , 0.79 and 0.86 at 600,625 and $650^{\circ} \mathrm{C}$, respectively. But, much like the case of hydrogen, a minor impact of the shift reaction on the carbon dioxide partial pressure dependency is found in Fig. 5b. For the gases at complete shift equilibrium, the reaction order increases from 0.59 to 0.80 with temperature.

In Fig. 6a the dependence of the exchange current density on the partial pressure of water is analyzed. The evaluation is done in two ways as discussed for hydrogen above. For the first case (solid lines), the reaction order of water increases from 0.59 to 0.78 at $600-650^{\circ} \mathrm{C}$. In the second case (dashed lines), the dependence values are in the range of $0.47-0.67\left(c^{1}\right)$ at the $\mathrm{H}_{2} \mathrm{O}$ concentration of $10-30 \%$, while the reaction order increases to the interval of $0.83-1.07\left(c^{2}\right)$ at 30 $50 \% \mathrm{H}_{2} \mathrm{O}$ at these operating temperatures. In contrast to hydrogen and carbon dioxide, the shift reaction has an important influence on the reaction order of water in electrolysis operation. The exchange current densities as function of water partial pressure after equilibrium, in Fig. 6b, more or less follow a straight line for each temperature. The values of reaction order for water are given by the slopes and are $0.82,0.94$ and 1.13 at 600,625 and $650^{\circ} \mathrm{C}$, respectively. These data approach the water partial pressure dependency with higher $\mathrm{H}_{2} \mathrm{O}$ concentration (30-50\%) in the inlet fuel gases.

If the reaction pathways of hydrogen production are assumed to take place exactly as the reverse process of hydrogen oxidation in molten carbonate salts, the theoretical partial pressure dependencies of hydrogen, carbon dioxide and water would be the same in both operating modes. When compared to reaction orders for hydrogen oxidation mentioned in Table I, the experimentally obtained data for water electrolysis are still higher. But the partial pressure dependencies evaluated in this study are rather close to the result of Lindbergh et al., ${ }^{13} 0.5$ for hydrogen and carbon dioxide, and 0.7 for water in fuel cell operation. Since similar porous electrode materials were used and analyzed by polarization data in both studies, it implies that hydrogen production in MCEC mode may be the reversed reaction of hydrogen oxidation in fuel cell operation. When taking the water-gas shift reaction into account, it is found that water shows higher reaction order

Table VI. The dependency of exchange current densities on the partial pressure of the gas compositions calculated at shift equilibrium $i_{0}=i_{0}^{0}\left(p_{\mathrm{H}_{2}}\right)^{a}\left(p_{\mathrm{CO}_{2}}\right)^{b}\left(p_{\mathrm{H}_{2}} \mathrm{O}\right)^{c}$. The superscripts 1 and 2 refer to the low and high concentration.

$a$

\begin{tabular}{cccccc}
\cline { 2 - 5 } Temperature $/{ }^{\circ} \mathrm{C}$ & $a$ & $a^{1}\left(3.5-20 \% \mathrm{H}_{2}\right)$ & $a^{2}\left(20-42 \% \mathrm{H}_{2}\right)$ & $b$ & $c$ \\
\hline 600 & 0.55 & 0.47 & 0.74 & 0.59 & 0.82 \\
625 & 0.56 & 0.42 & 0.87 & 0.74 & 0.94 \\
650 & 0.53 & 0.41 & 0.86 & 0.80 & 1.13
\end{tabular}

for hydrogen production than does carbon dioxide and hydrogen. The reaction mechanisms for hydrogen production in molten carbonate salts, following the reverse steps of hydrogen oxidation in the fuel cell, are suggested and discussed below.

When considering the hydrogen oxidation mechanism proposed by Ang and Sammells ${ }^{7}$ and Jewulski and Suski, ${ }^{8}$ the processes of hydrogen production in electrolysis operation are expressed as Reactions 8-10 and Reactions 11, 12 and 10, respectively. The method for derivation of the theoretical reaction orders is given in Refs. 7 and 22. The symmetry factor, as generally found, is assumed to be $\beta=0.5$ for the rate-determining step. The theoretical partial pressure dependencies are all derived as 0.25 for hydrogen, carbon dioxide and water, if the rate-determining step is Reaction 9 or Reaction 12, respectively, and a low coverage of $M H$ is assumed (M denotes metal). The last step for both reaction mechanisms is the chemical hydrogen evolution reaction. The theoretical values based on these two mechanisms are not consistent with our experimental data.

$$
\begin{gathered}
\mathrm{H}_{2} \mathrm{O}+\mathrm{M}+\mathrm{e}^{-} \rightleftharpoons \mathrm{MH}+\mathrm{OH}^{-} \\
\mathrm{OH}^{-}+\mathrm{CO}_{2}+\mathrm{M}+e^{-} \rightleftharpoons \mathrm{MH}+\mathrm{CO}_{3}^{2-} \\
2 \mathrm{MH} \rightleftharpoons \mathrm{H}_{2}+2 \mathrm{M} \\
\mathrm{H}_{2} \mathrm{O}+\mathrm{CO}_{3}^{2-} \rightleftharpoons 2 \mathrm{OH}^{-}+\mathrm{CO}_{2} \\
2\left(\mathrm{OH}^{-}+\mathrm{CO}_{2}+\mathrm{M}+e^{-} \rightleftharpoons \mathrm{MH}+\mathrm{CO}_{3}^{2-}\right) \\
2 \mathrm{MH} \rightleftharpoons \mathrm{H}_{2}+2 \mathrm{M}
\end{gathered}
$$

Lu and Selman ${ }^{9}$ confirmed the AS mechanism and indicated the importance of the hydrolysis equilibrium. The hydrolysis constant of Reaction 11 is reported to be $\mathrm{K}_{\mathrm{h}}=1.79 \cdot 10^{-4}$ for $650^{\circ} \mathrm{C}$. $^{9}$ On the basis of that, the hydrogen production reaction can be written as follows:

$$
\begin{gathered}
\mathrm{H}_{2} \mathrm{O}+\mathrm{CO}_{3}^{2-} \rightleftharpoons 2 \mathrm{OH}^{-}+\mathrm{CO}_{2} \\
\mathrm{H}_{2} \mathrm{O}+\mathrm{M}+e^{-} \rightleftharpoons \mathrm{MH}+\mathrm{OH}^{-} \\
\mathrm{OH}^{-}+\mathrm{CO}_{2}+\mathrm{M}+e^{-} \rightleftharpoons \mathrm{MH}+\mathrm{CO}_{3}^{2-} \\
2 \mathrm{MH} \rightleftharpoons \mathrm{H}_{2}+2 \mathrm{M}
\end{gathered}
$$

If Reaction 8 occurs rather slowly, the $\mathrm{OH}^{-}$ions provided for Reaction 9 will be from the hydrolysis Reaction 11 . In that case the electroreduction of water with hydrogen adsorption 8 becomes the rate-determining step, a high reaction order of water is obtained, $\frac{2-\beta}{2}$, or about 0.75 , and the values of 0.25 and -0.25 are theoretically obtained for hydrogen and carbon dioxide, respectively. The theoretical water partial pressure dependency seems close to the experimental data $(0.82-1.13)$. But the derived negative dependence $(-0.25)$ for carbon dioxide does not show agreement with the positive one obtained from the experimental results. If assuming Reaction 9 as the rate-determining step, all the reaction orders are $\frac{\beta}{2}$ or about 0.25 . Under the assumption that Reactions 8 and 9 take place simultaneously rather than as consecutive steps of a simple reaction, the possible conclusion is that the reaction order for hydrogen is still 0.25 , for 
carbon dioxide somewhere between -0.25 and 0.25 , and for water between 0.75 and 0.25 . But these value ranges are all lower than the data determined experimentally.

Next, the mechanism of hydrogen production is based on the reversed reaction of hydrogen oxidation suggested by Weewer et al., ${ }^{12}$ expressed as Reactions 11, 9 and 13.

$$
\begin{gathered}
\mathrm{H}_{2} \mathrm{O}+\mathrm{CO}_{3}^{2-} \rightleftharpoons 2 \mathrm{OH}^{-}+\mathrm{CO}_{2} \\
\mathrm{OH}^{-}+\mathrm{CO}_{2}+\mathrm{M}+e^{-} \rightleftharpoons \mathrm{MH}+\mathrm{CO}_{3}^{2-} \\
\mathrm{MH}+\mathrm{OH}^{-}+\mathrm{CO}_{2}+e^{-} \rightleftharpoons \mathrm{H}_{2}+\mathrm{CO}_{3}^{2-}
\end{gathered}
$$

Weewer et al. ${ }^{12}$ discussed that the Reaction 11 might be the ratedetermining step for hydrogen oxidation on a Ni flag electrode, due to the high reaction order of 1.5 found for $\mathrm{H}_{2} \mathrm{O}$. If Reaction 11 is also the rate-determining step for hydrogen production on the $\mathrm{Ni}$ porous electrode, the theoretical reaction orders will be zero for hydrogen and carbon dioxide, and 1 for water. A possibility is that a chemical reaction or the combination of a chemical reaction and electrochemical reactions is the rate-determining step in the porous electrode, due to the slow rate of the chemical reaction. But in this case it does not make sense concerning the dependency values of hydrogen and carbon dioxide, i.e. no dependence occurs in the hydrogen production process. If Reaction 9 is assumed to be the rate-determining step, as discussed above, identical reaction orders of 0.25 apply for $\mathrm{H}_{2}$, $\mathrm{CO}_{2}$ and $\mathrm{H}_{2} \mathrm{O}$. Assuming Reaction 13 to be rate-determining, a high reaction order of 0.75 is found for hydrogen, and of 0.25 for both carbon dioxide and water.

From the experimentally obtained reaction orders for hydrogen, carbon dioxide and water, regardless of shift equilibrium or not, they do not reasonably satisfy any of the four mechanisms suggested above for hydrogen production on a Ni porous electrode. Based on the reverse pathways of hydrogen oxidation, these mechanisms concern flag electrodes. Thus different characteristics of the surface area on a porous electrode may affect the electrode kinetics and reaction mechanism. Additionally, in this study the polarization analysis is based on the assumption that the $\mathrm{Ni}$ electrode is mainly under kinetic control at low overpotential, where mass-transfer limitations are neglected. However, the performance of the Ni electrode in the lab-scale cell, at least in fuel cell mode, could be affected by the gas phase mass transfer even at low overpotential, due to possibly not negligible concentration gradients in the current collector. ${ }^{21}$ This may also be the case at the $\mathrm{Ni}$ electrode in electrolysis cell mode. Another possible factor is that the effect of gas composition on the electrolyte wetting properties is not taken into consideration when analyzing the polarization data. The wetting angle will affect the active surface area, and therefore it probably changes the available active surface area for the faradaic reaction. ${ }^{23}$ The partial pressure dependencies will be changed, if the active surface area or/and the effective conductivity is/are dependent on the gas compositions. ${ }^{13}$

The number of transferring electrons has no impact on the reaction orders, although changing $n$ will change the value of the exchange current density. In the MCEC mode, water electrolysis may not be the only reaction process in the cell. The electrolysis of carbon dioxide is not considered in this analysis of kinetic data. But due to the high reaction order of $\mathrm{CO}_{2}(0.59-0.86)$, it is still another possible reaction occurring in the cell. Therefore, future studies will be performed to determine the occurrence of electrolysis of carbon dioxide on the $\mathrm{Ni}$ porous electrode. To study the reaction mechanism in more detail and more accurately, other electrochemical techniques could also be employed to measure electrode performance and make qualitative comparisons.

According to the Arrhenius equation, the activation energy $\left(E_{a}\right)$ can be calculated from the following relationship:

$$
E_{a}=-2.303 R \frac{d\left(\log i_{0}\right)}{d(1 / T)}
$$

For gas compositions in group 1, containing 5-50\% hydrogen, the obtained activation energy is in the range of $65-85 \mathrm{~kJ} \cdot \mathrm{mol}^{-1}$. The activation energy does not strongly depend on the hydrogen concentration. When increasing the carbon dioxide and water from 10 to $50 \%$ individually, the activation energy shows an increase, now ranging from 55 to $100 \mathrm{~kJ} \cdot \mathrm{mol}^{-1}$ for these two groups of gas compositions. The activation energy could be a clue to determining the rate-limiting process in the fuel cell, ${ }^{24}$ and may also be used when evaluating the $\mathrm{Ni}$ electrode as cathode in the molten carbonate electrolysis cell. The activation energy obtained in the present study indicates that the $\mathrm{Ni}$ electrode is under kinetic or mixed control. This differs from the ratelimiting process in fuel cell mode, in which the porous Ni electrode anode is usually under mass-transfer limitation. ${ }^{11}$

\section{Conclusions}

The polarization data for the Ni porous electrode in a molten carbonate electrolysis cell were investigated under different gas compositions at three different temperatures. The exchange current densities were evaluated numerically from the slopes of the polarization curves at low overpotential, assuming that the electrode was under kinetic control.

The partial pressure dependencies for hydrogen, carbon dioxide and water were determined in two cases, no water-gas shift reaction and complete shift equilibrium. The reaction order of hydrogen was found in the range of $0.49-0.44$ at low $\mathrm{H}_{2}$ concentration from 600 to $650^{\circ} \mathrm{C}$, changing to the interval $0.79-0.94$ when containing $25-50 \%$ $\mathrm{H}_{2}$ in the inlet gas. The partial pressure dependency of carbon dioxide increased from 0.62 to 0.86 with the increase of temperature. The reversed water-gas shift reaction has a minor or almost no impact on the electrochemical reaction order of hydrogen and carbon dioxide. The reaction order of water was analyzed in two ways, just as for hydrogen. At lower $\mathrm{H}_{2} \mathrm{O}$ concentration, $10-30 \%$ in the inlet gases, the reaction order was in the range of $0.47-0.67$ while it increased to $0.83-1.07$ for $30-50 \% \mathrm{H}_{2} \mathrm{O}$ at $600-650^{\circ} \mathrm{C}$. The shift reaction plays a major role in the water partial pressure dependency. The reaction order was found to be within the range of $0.82-1.13$ at shift equilibrium in the temperature interval $600-650^{\circ} \mathrm{C}$, approaching the results at higher water content.

There were four reaction mechanisms suggested and discussed concerning hydrogen production in a molten carbonate electrolysis cell, based on the reversed process of hydrogen oxidation in fuel cell operation. However, the experimentally obtained reaction orders were high and therefore not consistent with the mechanisms suggested above. The interpretation of polarization data and the evaluation of exchange current densities were dependent on assumptions made about the surface area and the effective conductivities. The reaction orders could be affected if these two factors were dependent on gas compositions and incorrect assumptions were made. It is also necessary to take into consideration the effect of mass-transfer limitations on the performance of the Ni electrode, even though it is assumed to be negligible at low overpotential. Another explanation for this divergence between experimental data and theoretical calculation might be the possibility of co-electrolysis of water and carbon dioxide rather than purely water electrolysis.

The activation energy of the $\mathrm{Ni}$ porous electrode for hydrogen production lies between 55 and $100 \mathrm{~kJ} \cdot \mathrm{mol}^{-1}$ for all the different gas compositions, indicating that the Ni electrode was under kinetic or mixed control.

\section{Acknowledgment}

The financial support of the China Scholarship Council (CSC) is appreciated. The cell components were provided by Ansaldo Fuel Cells in Italy.

\section{List of Symbols}

F $\quad$ Faraday's number, $\mathrm{C} \cdot \mathrm{mol}^{-1}$

$i \quad$ current density, $\mathrm{A} \cdot \mathrm{m}^{-2}$

$i_{0} \quad$ exchange current density, $\mathrm{A} \cdot \mathrm{m}^{-2}$

$i_{0}^{0} \quad$ standard exchange current density 
$n \quad$ number of electrons

$p \quad$ partial pressure, atm

$\mathrm{R} \quad$ gas constant, $\mathrm{J} \cdot \mathrm{mol}^{-1} \cdot \mathrm{K}^{-1}$

$S \quad$ specific surface area, $\mathrm{m}^{-1}$

$T \quad$ temperature, $\mathrm{K}$

$b$

$c$

partial pressure dependency of hydrogen in MCEC

partial pressure dependency of carbon dioxide in MCEC partial pressure dependency of water in MCEC

\section{Greek}

$\alpha_{A}$

anodic transfer coefficient

cathodic transfer coefficient

symmetry factor

partial pressure dependency of hydrogen in MCFC

partial pressure dependency of carbon dioxide in MCFC

partial pressure dependency of water in MCFC

effective conductivity of the electrolyte, $\mathrm{S} \cdot \mathrm{m}^{-1}$

overpotential, $\mathrm{V}$

\section{References}

1. Y. Tao, H. Nishino, S. Ashidate, H. Kokubo, M. Watanabe, and H. Uchida, Elec trochim. Acta, 54, 3309 (2009).

2. W. H. A. Peelen, K. Hemmes, and J. H. W. de Wit, Electrochim. Acta, 43, 763 (1997)
3. V. Kaplan, E. Wachtel, K. Gartsman, Y. Feldman, and I. Lubomirsky, J. Electrochem. Soc., 157, B552 (2010)

4. V. Kaplan, E. Wachtel, and I. Lubomirsky, J. Electrochem. Soc., 159, E159 (2012).

5. D. Chery, V. Albin, V. Lair, and M. Cassir, Int. J. Hydrogen Energy, 39, 12330 (2014).

6. L. Hu, I. Rexed, G. Lindbergh, and C. Lagergren, Int. J. Hydrogen Energy, 39, 12323 (2014).

7. P. G. P. Ang and A. F. Sammells, J. Electrochem. Soc., 127, 1287 (1980).

8. J. Jewulski and L. Suski, J. Appl. Electrochem., 14, 135 (1984).

9. S. H. Lu and J. R. Selman, J. Electrochem. Soc., 131, 2827 (1984).

10. T. Nishina, M. Takahashi, and I. Uchida, J. Electrochem. Soc., 137, 1112 (1990)

11. C. Y. Yuh and J. R. Selman, J. Electrochem. Soc., 138, 3649 (1991).

12. R. Weewer, K. Hemmes, and J. H. W. de Wit, J. Electrochem. Soc., 142, 389 (1995).

13. G. Lindbergh, M. Olivry, and M. Sparr, J. Electrochem. Soc., 148, A411 (2001).

14. S. D. Ebbesen, R. Knibbe, and M. Mogensen, J. Electrochem. Soc., 159, F482 (2012).

15. S. H. Clarke, A. L. Dicks, K. Pointon, T. A. Smith, and A. Swann, Catal. Today, 38, 411 (1997).

16. C. Lagergren and D. Simonsson, J. Electrochem. Soc., 144, 3813 (1997).

17. C. Lagergren, Electrochemical performance of porous MCFC cathodes, Ph.D. Thesis, KTH Royal Institute of Technology, Sweden (1997).

18. S. Tanase, Y. Miyazaki, M. Yanagida, K. Tanimoto, and T. Kodama, Prog. Batt. Sol. Cells, 6, 195 (1987).

19. M. Sparr, Modelling and experimental investigation of the porous nickel anode in the molten carbonate fuel cell, Ph.D. Thesis, KTH Royal Institute of Technology, Sweden (2005).

20. M. Kawase, Y. Mugikura, and T. Watanabe, J. Electrochem. Soc., 147, 854 (2000).

21. M. Sparr, A. Bodén, and G. Lindbergh, J. Electrochem. Soc., 153, A1525 (2000).

22. R. Weewer, Study of electrochemcal processes and wetting phenomena at the molten carbonate fuel cell anode, Ph.D. Thesis, Delft University of Technology, Netherlands (1990).

23. M. Yoshikawa, A. Bodén, M. Sparr, and G. Lindbergh, J. Power Sources, 158, 94 (2006).

24. C. Y. Yuh and J. R. Selman, J. Electrochem. Soc., 138, 3642 (1991) 